\title{
Peripheral artery disease in peritoneal dialysis and hemodialysis patients: single-center retrospective study in Taiwan
}

\author{
Chun-Chuan Lee ${ }^{1}$, Chih-Jen Wü2,4 Li-Hua Chou ${ }^{3}$, Su-Mei Shen ${ }^{3}$, Sheng-Fang Chiang ${ }^{3}$, Pi-Chu Jen ${ }^{3}$, \\ Mei-Ching Yeh ${ }^{3}$ and Chi-Feng Pan ${ }^{2,5^{*}}$
}

\begin{abstract}
Background: Peripheral artery disease (PAD) is a condition characterized by restricted blood flow to the extremities, and is especially common in the elderly. PAD increases the risk for mortality and morbidity in patients with end-stage renal disease (ESRD), especially those on hemodialysis (HD).

Methods: The records of 484 patients with end-stage renal disease who were on HD or peritoneal dialysis (PD) were reviewed. PAD was diagnosed based on the ankle-brachial pressure index (ABI). Demographic and clinical characteristics were analyzed.
\end{abstract}

Results: PAD had an overall prevalence of $18.2 \%$ and was significantly more common in HD patients (21.8\%) than in PD patients (4.8\%). Advanced age, diabetes mellitus, smoking, low parathyroid hormone level, elevated serum ferritin, elevated serum glucose, and low serum creatinine levels increased the risk for PAD. PAD was independently associated with advanced age, diabetes mellitus, duration of dialysis, low serum creatinine, and hyperlipidemia. PD patients had a significantly lower prevalence of PAD than HD patients, maybe due to their younger age and lower prevalence of diabetes mellitus in this present study.

Conclusions: The prevalence of PAD was greater in the HD group than the PD group. Most of the risk factors for PAD were specific to HD, and no analyzed factor was significantly associated with PAD in PD patients.

Keywords: Ankle-brachial pressure index (ABI), Cardiovascular disease, End-stage renal disease, Hemodialysis, Peritoneal dialysis, Peripheral artery disease

\section{Background}

Cardiovascular disease is the most common cause of death in patients with end-stage renal disease (ESRD) [1]. Peripheral artery disease (PAD) is an important marker of systemic atherosclerosis, and often leads to significant morbidity and mortality, particularly in patients with ESRD [2]. The National Health and Nutrition Examination Survey (NHANES) of 1999-2000 reported that PAD affects approximately 5 million adults, including $12-20 \%$ of Americans aged 65 years and older [3]. The prevalence of PAD increases dramatically with age,

\footnotetext{
* Correspondence: pan530319@yahoo.com.tw

${ }^{2}$ Division of Nephrology, Department of Internal Medicine, Mackay Memorial Hospital, Taipei, Taiwan

${ }^{5}$ Mackay Medicine, Nursing and Management College, Taipei, Taiwan

Full list of author information is available at the end of the article
}

but the actual prevalence may be underestimated. Experts have estimated that PAD affects approximately 8 million people in the U.S. alone [4]. In contrast, little is known about the prevalence of PAD in Asian ESRD patients.

Despite the high prevalence of PAD and its association with increased cardiovascular disease, few PAD patients are given treatment for this condition, because most are asymptomatic [5]. PAD often progresses silently until the onset of the most common symptom, intermittent claudication [2]. However, in the general population, only about $10 \%$ of patients with PAD develop this classic symptom, about $40 \%$ have no complaint of leg pain, and about $50 \%$ have diverse leg symptoms that are not typical of classic claudication [4].

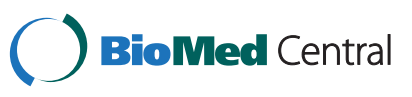

(c) 2012 Lee et al.; licensee BioMed Central Ltd. This is an Open Access article distributed under the terms of the Creative Commons Attribution License (http://creativecommons.org/licenses/by/2.0), which permits unrestricted use, distribution, and reproduction in any medium, provided the original work is properly cited. 
PAD is considered a marker for systemic atherosclerotic disease. Patients with PAD have a four-to-five fold greater risk of dying from a cardiovascular event and a two-to-three fold higher overall mortality rate relative to patients without PAD [6]. The irreversible and reversible risk factors associated with PAD are similar to those for ischemic heart disease [7]. Although younger patients represent a small percentage of PAD cases, they have poorer long-term outcome and experience more complications associated with bypass revascularization surgery [6]. There is a remarkably high prevalence of PAD in patients with renal insufficiency [8]. In particular, 24\% of the NHANES population older than 40 years with renal insufficiency had PAD, but only $3.7 \%$ with normal renal function had PAD, and this association was independent of diabetes, hypertension, and age [8].

Increased duration of dialysis and conventional cardiovascular disease risk factors (other than hypertension and hyperlipidemia) are known risk factors for PAD [8]. PAD has been diagnosed in $25.3 \%$ of ESRD patients, and the prevalence varied widely among different populations [5]. A recent study of patients on maintenance ambulatory peritoneal dialysis (PD) indicated the prevalence of PAD was $27.4 \%$ of all patients, and was $45 \%$ in patients older than 70 years [9].

The ankle-brachial pressure index $(A B I)$ is the simplest, least expensive, and most reliable method of detecting atherosclerosis in asymptomatic individuals with suspected PAD [10]. Numerous clinical and epidemiological studies have used the ABI to screen for PAD because PAD of the lower extremities is associated with poor overall prognosis [11,12]. In the U.S., the prevalence of PAD is much higher in patients on hemodialysis (HD) than in age- and sex-matched healthy subjects [11]. A Finnish study indicated the prevalence of an elevated ABI was $8.4 \%$ among patients referred for vascular consultation and that PAD was much more common in patients with renal failure [13]. However, there is little available data on relationship of PAD and renal failure in Asian populations, and fewer data in PD patients.

In the present study, we compared $\mathrm{HD}$ and $\mathrm{PD}$ patients who were receiving maintenance dialysis in the Mackay Memorial Hospital (Taipei, Taiwan) to identify the prevalence and risk factors associated with PAD in ESRD patients and to compare prevalence and risk of PAD in HD and PD patients.

\section{Methods}

Between June 1, 2007 and September 30, 2007, 529 patients with ESRD were on maintenance dialysis in the Dialysis Unit of Mackay Memorial Hospital. A total of 45 patients had severe illnesses, such as liver cirrhosis, malignancies, apparent acute inflammatory diseases, or amputation of both legs and were excluded. ABI was recorded for the remaining 484 patients, which included $380 \mathrm{HD}$ patients (all with synthetic membranes) and 104 PD patients (median [IQR] urea clearance, 2.27 L/Day [0-20.52]). The Institutional Review Board of Mackay Memorial Hospital approved this retrospective study of the records of these patients. All patients had undergone dialysis for at least 3 months prior to enrollment.

The following basic data was recorded for all subjects at baseline: age, gender, height, weight, BMI $\left(\mathrm{kg} / \mathrm{m}^{2}\right)$, and duration and mode of dialysis. Analysis of risk factors associated with PAD considered the effect of smoking (ever versus never), cardiovascular or cerebrovascular disease (CVD), hypertension, diabetes, hyperlipidemia, and underlying renal disease. Dialysis dose was calculated from Daugirdas formula for $\mathrm{Kt} / \mathrm{V}$ and serum assays were performed for intact parathyroid hormone (iPTH), hematocrit (Hct), fasting glucose, blood urea nitrogen $(\mathrm{BUN})$, creatinine $(\mathrm{Cr})$, calcium $(\mathrm{Ca})$, phosphorus $(\mathrm{P})$, calcium and phosphorus product $(\mathrm{Ca} \times \mathrm{P})$, albumin, cholesterol, triglyceride (TG), total carbon dioxide $\left(\mathrm{TCO}_{2}\right)$, and ferritin. Both groups were given the minimal recommended doses of dialysis and the presented $\mathrm{Kt} / \mathrm{V}$ results indicate the $\mathrm{Kt} / \mathrm{V}$ per dialysis session.

The ABI ratio was calculated with the Fukuda Vascular Screening system (VaSera VS-1000 ${ }^{\mathrm{rm}}$, Fukuda Denshi Co., Ltd., Tokyo, Japan) and were performed while the subjects were supine. Systolic blood pressure was measured at the brachial artery on the nondialytic vascular access arm and on both ankles (at the posterior tibial arteries). PAD was diagnosed if ABI was less than 0.9 in either lower extremity. A patient was assigned a score of "PAD-one" if the $\mathrm{ABI}$ was low in one lower extremity and a score of "PAD-two" if the ABI was low in both lower extremities.

\section{Statistical analysis}

For continuous variables, data are presented as means \pm standard deviations (SDs) and an independent twosample $t$-test was used to compare the $\mathrm{HD}$ and $\mathrm{PD}$ groups. If variables were not normally distributed, data is presented as medians and interquartile ranges (IQRs) and the Mann-Whitney $U$ test was used for comparisons. For categorical variables, data are presented as number (percentage) and the Chi-square test was used for comparisons of the two binary variables. Logistic regression analysis was used to identify factors related to the presence of PAD. Variables associated with PAD based on univariate analysis were entered into multivariate models. All statistical assessments were two-sided and a $p$-value less than 0.05 was considered significant. Statistical analyses were performed using SPSS 15.0 (SPSS Inc., Chicago, IL). 


\section{Results}

Table 1 shows the demographic and clinical characteristics of the 484 ESRD patients who were on HD or PD in the dialysis unit of Mackay Memorial Hospital from June 1, 2007 to September 30, 2007. There were 213 males and 271 females, the mean age was $57.91 \pm 13.64$ years (range: 21 to 90 years), and there were 380 patients undergoing $\mathrm{HD}(78.5 \%)$ and 104 patients undergoing $\mathrm{PD}$ (21.5\%). The overall prevalence of PAD was $18.2 \%$ $(n=88)$. There were statistically significant differences between the two groups with regard to age (HD: $60.39 \pm$ 12.81 years, PD: $48.87 \pm 12.76$ years, $p<0.001)$, median duration of dialysis (HD: 55 months, PD: 36 months, $p<0.001$ ), history of DM (HD: $36.6 \%$, PD: $18.3 \%$, $p<0.0001$ ), smoking status (HD: $36.6 \%$, PD: $14.4 \%$, $p=0.003$ ), and in the overall prevalence of PAD (HD:
21.8\%, PD: 4.8\%). The prevalence of PAD in one extremity (HD: $11.8 \%$, PD: $1.9 \%$ ) and in two extremities (HD: $10.0 \%$, PD: $2.9 \%$ ) were greater in the HD group $(p<0.001)$ In addition, the HD group had significantly higher levels of Hct, albumin, ferritin, uric acid $(p<0.05$ for all) and significantly lower levels of $\mathrm{Kt} / \mathrm{V}$ per dialysis session, $\mathrm{TCO}_{2}$, cholesterol, blood sugar, $\mathrm{Cr}, \mathrm{Ca}, \mathrm{P}$ and $\mathrm{Ca} \times \mathrm{P}(p<0.05$ for all $)$.

Figure 1 shows the frequency distributions of our ABI measurements. There were no significant differences in the mean \pm SD of the left and right $\mathrm{ABI}$ among $\mathrm{HD}$ patients or in the mean \pm SD of the left and right $A B I$ among PD patients. However, HD patients had a significantly lower mean ABI $(p=0.047)$.

Table 2 shows the demographic and clinical characteristics of ESRD patients with and without PAD. PAD

Table 1 Clinical and demographic characteristics of hemodialysis (HD) and peritoneal dialysis (PD) patients $(n=484)$

\begin{tabular}{|c|c|c|c|c|}
\hline Variables & Total $(n=484)$ & HD group $(n=380)$ & PD group $(n=104)$ & P-value \\
\hline Age (years) $^{1}$ & $57.91 \pm 13.64$ & $60.39 \pm 12.81$ & $48.87 \pm 12.76$ & $<0.001^{*}$ \\
\hline Gender, $\mathrm{n}(\%)^{2}$ & & & & 0.131 \\
\hline Male & $213(44.0)$ & $174(45.8)$ & $39(37.5)$ & \\
\hline Female & $271(56.0)$ & $206(54.2)$ & $65(62.5)$ & \\
\hline $\mathrm{BMI}\left(\mathrm{kg} / \mathrm{m}^{2}\right)^{1}$ & $22.49 \pm 3.43$ & $22.44 \pm 3.34$ & $22.67 \pm 3.77$ & 0.533 \\
\hline Duration of Dialysis (months) ${ }^{3}$ & $48(26,88)$ & $55(31,94)$ & $36(14,57)$ & $<0.001^{*}$ \\
\hline $\mathrm{DM}, \mathrm{n}(\%)^{2}$ & 158 (32.6) & 139 (36.6) & 19 (18.3) & $<0.001^{*}$ \\
\hline $\mathrm{HT}, \mathrm{n}(\%)^{2}$ & $356(73.6)$ & $280(73.7)$ & $76(73.1)$ & 0.901 \\
\hline Hyperlipidemia, n (\%) & $199(41.1)$ & $149(39.2)$ & $50(48.1)$ & 0.103 \\
\hline Smoking, n (\%) ${ }^{2}$ & 124 (25.6) & $109(28.7)$ & $15(14.4)$ & $0.003^{*}$ \\
\hline PAD, n (\%) $)^{2}$ & & & & $<0.001^{*}$ \\
\hline Non & $396(81.8)$ & $297(78.2)$ & $99(95.2)$ & \\
\hline PAD-one & $47(9.7)$ & $45(11.8)$ & $2(1.9)$ & \\
\hline PAD-two & $41(8.5)$ & $38(10.0)$ & $3(2.9)$ & \\
\hline Daugirdes Kt $/ N$ per dialysis session ${ }^{1}$ & $1.90 \pm 0.40$ & $1.81 \pm 0.35$ & $2.22 \pm 0.41$ & $<0.001^{*}$ \\
\hline Hct $(\%)^{1}$ & $30.10 \pm 4.36$ & $30.37 \pm 4.12$ & $29.13 \pm 5.04$ & $0.023^{*}$ \\
\hline $\mathrm{TCO}_{2}(\mathrm{mmol} / \mathrm{L})^{1}$ & $23.54 \pm 2.87$ & $22.71 \pm 2.32$ & $26.60 \pm 2.60$ & $<0.001^{*}$ \\
\hline Albumin $(\mathrm{g} / \mathrm{dL})^{1}$ & $3.94 \pm 0.38$ & $3.97 \pm 0.37$ & $3.80 \pm 0.39$ & $<0.001^{*}$ \\
\hline i-PTH $(p g / m L)^{3}$ & $284.8(163.4,480.7)$ & $281.7(166.2,468.9)$ & $328.9(160.7,512.0)$ & 0.541 \\
\hline Ferritin $(\mathrm{ng} / \mathrm{mL})^{3}$ & $573.0(364.0,761.7)$ & $632.8(487.5,799.6)$ & $330.7(173.1,482.1)$ & $<0.001^{*}$ \\
\hline Cholesterol $(\mathrm{mg} / \mathrm{dL})^{3}$ & $183(154,209)$ & $179(151,205)$ & $190(172,213)$ & $0.012^{*}$ \\
\hline TG $(\mathrm{mg} / \mathrm{dL})^{3}$ & $125(82,195)$ & $124(82,194)$ & $130(82,232)$ & 0.372 \\
\hline Fasting blood sugar $(\mathrm{mg} / \mathrm{dL})^{3}$ & $95(83,117)$ & $90(81,117)$ & $104(95,116)$ & $<0.001^{*}$ \\
\hline $\mathrm{Cr}(\mathrm{mg} / \mathrm{dL})^{1,4}$ & $11.01 \pm 2.77$ & $10.61 \pm 2.44$ & $12.44 \pm 3.40$ & $<0.001^{*}$ \\
\hline Uric Acid $(\mathrm{mg} / \mathrm{dL})^{1}$ & $7.23 \pm 1.30$ & $7.35 \pm 1.31$ & $6.80 \pm 1.15$ & $<0.001^{*}$ \\
\hline $\mathrm{Ca}(\mathrm{mg} / \mathrm{dL})^{1}$ & $9.07 \pm 0.83$ & $8.97 \pm 0.79$ & $9.44 \pm 0.87$ & $<0.001^{*}$ \\
\hline$P(\mathrm{mg} / \mathrm{dL})^{1}$ & $5.41 \pm 1.38$ & $5.32 \pm 1.37$ & $5.73 \pm 1.36$ & $0.006^{*}$ \\
\hline $\operatorname{CaxP}(\mathrm{mg} / \mathrm{dL})^{1}$ & $49.16 \pm 13.64$ & $47.78 \pm 13.26$ & $54.15 \pm 13.90$ & $<0.001^{*}$ \\
\hline
\end{tabular}

* significant difference between groups $(p<0.05)$.

P-values were calculated by: ${ }^{1}$ Independent two sample $t$-test (mean $\pm \mathrm{SD}$ ); ${ }^{2} \mathrm{Chi}$-square test (number [percentage]); ${ }^{3} \mathrm{Mann}$-Whitney $\mathrm{U}$ test (median $[\mathrm{IQR}]$ ); ${ }^{4} \mathrm{Cr}$ was measured pre-dialysis. 


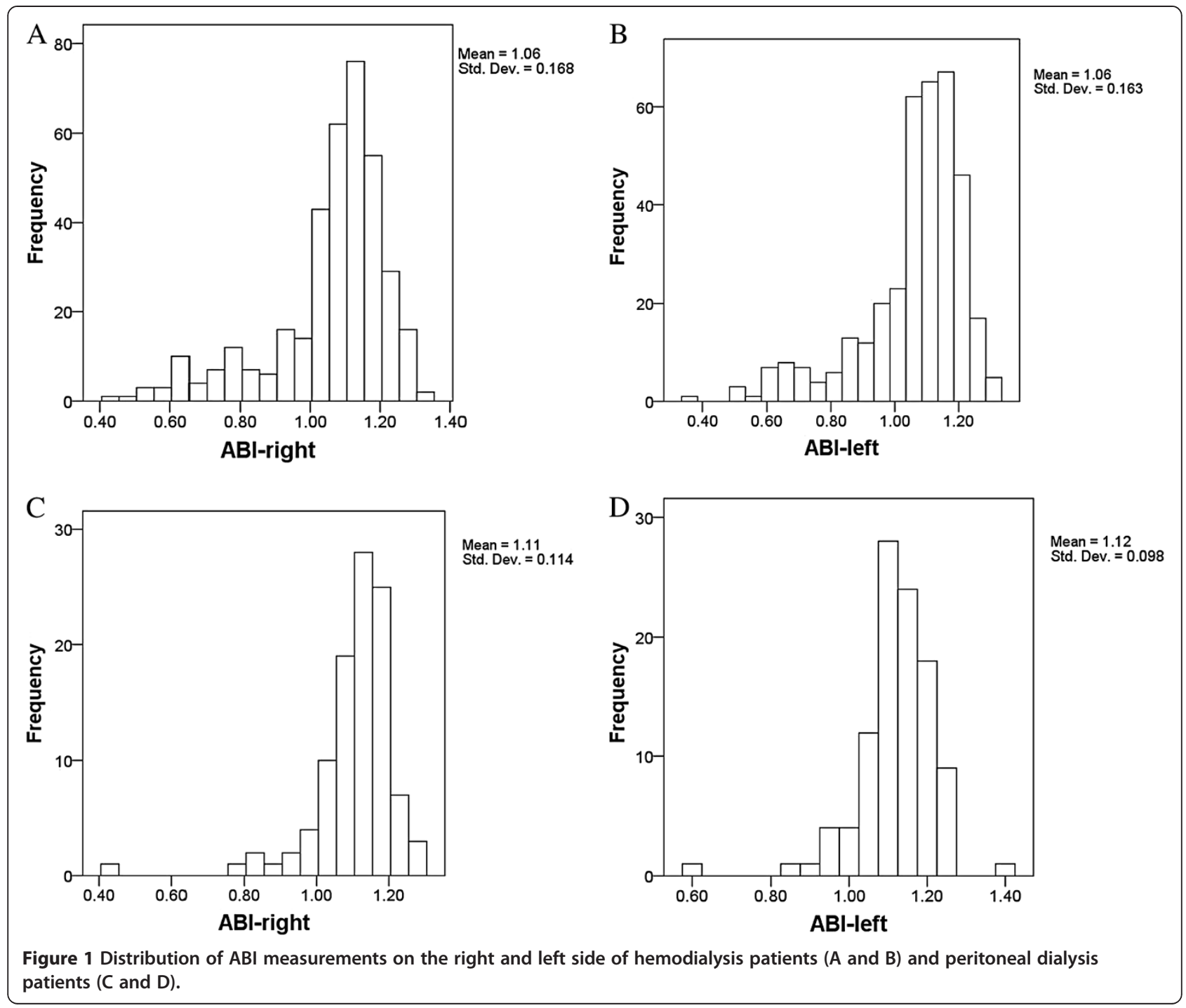

patients were more likely to have diabetes mellitus (61.4\% vs $26.3 \%, p<0.001)$, older $(68.66 \pm 10.54$ years $v s$ $55.52 \pm 13.10$ years, $p<0.001)$, smoke $(35.2 \%$ vs $23.5 \%$, $p=0.022$ ). Patients without PAD had higher levels of serum albumin, i-PTH, and $\mathrm{Cr}(p<0.05$ for all $)$ and patients with PAD had higher levels of ferritin and blood sugar ( $p<0.05$ for both).

Table 3 shows the results of univariate and multivariate logistic regression analysis of factors associated with PAD in all of the maintenance dialysis patients. Univariate analysis indicated that age, type of dialysis, $\mathrm{DM}$, smoking, albumin, i-PTH, ferritin, blood sugar, and $\mathrm{Cr}$ were significantly associated with PAD $(p<0.05$ for all). After controlling for age and DM history, multivariate logistic regression analysis indicated that for each $1 \mathrm{mg} / \mathrm{dL}$ elevation of $\mathrm{Cr}$, the odds for PAD were $15 \%$ lower $(\mathrm{OR}=0.85 ; 95 \%$ C.I. $=0.74$ to 0.98 ; $p=0.024)$.
Next, we used the same univariate and multivariate methods to separately analyze the risk factors for PAD in HD patients (Table 4) and PD patients (Table 5). Among HD patients, advanced age and history of DM were independently associated with PAD. Among PD patients, there were no factors significantly associated with PAD.

\section{Discussion}

We determined the prevalence of PAD in 484 Taiwanese ESRD patients from a single medical center and compared the characteristics of patients who were on HD with those on PD. Our results indicate that advanced age, presence of diabetes mellitus, and low serum creatinine were independently associated with the presence of PAD. Advanced age was the most significant risk factor for PAD (NonPAD: $55.52 \pm 13.10$, PAD: $68.66 \pm 10.54, p<0.001)$. The inverse 
Table 2 Clinical and demographic characteristics of all maintenance dialysis patients with and without peripheral arterial disease (PAD) $(n=484)$

\begin{tabular}{|c|c|c|c|}
\hline Variables & Non-PAD $(n=396)$ & $\operatorname{PAD}(n=88)$ & P-value \\
\hline$\overline{\text { Age }(\text { years) }}{ }^{1}$ & $55.52 \pm 13.10$ & $68.66 \pm 10.54$ & $<0.001^{*}$ \\
\hline Gender, $\mathrm{n}(\%)^{2}$ & & & 0.136 \\
\hline Male & $168(42.4)$ & $45(51.1)$ & \\
\hline Female & $228(57.6)$ & $43(48.9)$ & \\
\hline $\mathrm{BMI}\left(\mathrm{kg} / \mathrm{m}^{2}\right)^{1}$ & $22.53 \pm 3.56$ & $22.30 \pm 2.82$ & 0.566 \\
\hline Type of dialysis, $n(\%)^{2}$ & & & $<0.001^{*}$ \\
\hline $\mathrm{HD}$ & $297(75.0)$ & $83(94.3)$ & \\
\hline PD & $99(25.0)$ & $5(5.7)$ & \\
\hline Duration of Dialysis(months) ${ }^{3}$ & $47(25,86)$ & $57(27,96)$ & 0.318 \\
\hline $\mathrm{DM}, \mathrm{n}(\%)^{2}$ & $104(26.3)$ & $54(61.4)$ & $<0.001^{*}$ \\
\hline$H T, n(\%)^{2}$ & $292(73.7)$ & $64(72.7)$ & 0.846 \\
\hline Hyperlipidemia, n (\%) ${ }^{2}$ & $158(39.9)$ & $41(46.6)$ & 0.248 \\
\hline Smoking, $n(\%)^{2}$ & $93(23.5)$ & $31(35.2)$ & $0.022^{*}$ \\
\hline Daugirdes Kt/N $N^{1}$ & $1.91 \pm 0.39$ & $1.85 \pm 0.46$ & 0.218 \\
\hline Hct $(\%)^{1}$ & $30.02 \pm 4.50$ & $30.44 \pm 3.66$ & 0.418 \\
\hline $\mathrm{TCO}_{2}(\mathrm{mmol} / \mathrm{L})^{1}$ & $23.55 \pm 2.95$ & $23.51 \pm 2.45$ & 0.897 \\
\hline Albumin $(\mathrm{g} / \mathrm{dL})^{1}$ & $3.96 \pm 0.38$ & $3.84 \pm 0.38$ & $0.012^{*}$ \\
\hline i-PTH $(p g / m L)^{3}$ & $309.1(173.1,497.8)$ & $223.6(101.8,385.6)$ & $0.002^{*}$ \\
\hline Ferritin $(\mathrm{ng} / \mathrm{mL})^{3}$ & $559.2(354.0,754.3)$ & $651.3(479.1,846.8)$ & $0.017^{*}$ \\
\hline Cholesterol $(\mathrm{mg} / \mathrm{dL})^{3}$ & $183(154.5,204.5)$ & $178(150,216)$ & 0.915 \\
\hline $\mathrm{TG}(\mathrm{mg} / \mathrm{dL})^{3}$ & $122(82,192)$ & $137(81,213)$ & 0.398 \\
\hline Blood sugar $(\mathrm{mg} / \mathrm{dL})^{3}$ & $93(82,112)$ & $107(85,159)$ & $<0.001^{*}$ \\
\hline $\mathrm{Cr}(\mathrm{mg} / \mathrm{dL})^{1}$ & $11.38 \pm 2.67$ & $9.33 \pm 2.61$ & $<0.001^{*}$ \\
\hline Uric Acid $(\mathrm{mg} / \mathrm{dL})^{1}$ & $7.27 \pm 1.29$ & $7.05 \pm 1.33$ & 0.142 \\
\hline $\mathrm{Ca}(\mathrm{mg} / \mathrm{dL})^{1}$ & $9.07 \pm 0.84$ & $9.07 \pm 0.78$ & 0.990 \\
\hline$P(\mathrm{mg} / \mathrm{dL})^{1}$ & $5.46 \pm 1.35$ & $5.16 \pm 1.51$ & 0.064 \\
\hline $\operatorname{CaxP}(\mathrm{mg} / \mathrm{dL})^{1}$ & $49.66 \pm 13.42$ & $46.84 \pm 14.47$ & 0.081 \\
\hline
\end{tabular}

* significant difference between groups $(p<0.05)$.

P-values were calculated by: ${ }^{1}$ Independent two sample $t$-test (mean $\pm \mathrm{SD}$ ); ${ }^{2}$ Chi-square test (number [percentage]); and ${ }^{3} \mathrm{Mann}-\mathrm{Whitney} \mathrm{U}$ test (median [IQR]).

association of serum $\mathrm{Cr}$ and PAD may seem counterintuitive. We suggest that this may be due to the lower muscle mass or frailty of these patients. The higher serum $\mathrm{Ca}, \mathrm{P}$, and $\mathrm{Ca} \times \mathrm{P}$ were all significantly higher in PD patients, possibly because HD patients were usually on more restrictive diets.

Previous studies of Western populations indicated that PAD is much more common in patients with ESRD (17-48\%) than in the general population [14]. The documentation of declining ABI measurements in patients with suspected or known PAD can be an effective way to chart the patient prognosis. Previous studies indicated that this test has a sensitivity greater than $90 \%$ and a specificity of $95 \%$ for the diagnosis of PAD $[15,16]$. In particular, one study of 606 patients (mean age: 62years; $68 \%$ male) reported that major one-year decline in resting and post-exercise $\mathrm{ABI}$ were associated with all-cause mortality, cardiac events, stroke, kidney failure, and PAD [17].

Our study and other studies of PAD examined patients undergoing HD. However, a previous study of Spanish patients with chronic renal failure stages IV and V who were not undergoing dialysis reported that $19 \%$ of patients had PAD or other vascular pathologies and that the 5-year mortality rate was higher in patients with PAD than in those without PAD (64\% vs. 20\%) [18]. In addition, a previous study of Japanese subjects with type2 diabetes mellitus who were not undergoing HD reported that chronic kidney disease had a more significant impact on PAD than metabolic syndrome [19]. Finally, a study of U.S. subjects with no renal abnormalities (participants in the Iron [Fe] and Atherosclerosis Study Study [FeAST], Veterans Affairs [VA] Cooperative Study [CSP] \#410) reported significant associations between 
Table 3 Univariate and multivariate logistic regression analysis of risk factors associated with PAD in all maintenance dialysis patients $(n=484)$

\begin{tabular}{|c|c|c|c|}
\hline \multirow[t]{2}{*}{ Variables } & \multirow{2}{*}{$\frac{\text { Univariate }}{\text { OR (95\% C.I.) }}$} & \multirow{2}{*}{$\frac{\text { Multivariate }}{\text { OR (95\% C.I.) }}$} & \multirow[b]{2}{*}{ P-value } \\
\hline & & & \\
\hline Age & $1.09(1.07,1.12)^{*}$ & $1.08(1.05,1.11)$ & $<0.001^{*}$ \\
\hline \multicolumn{4}{|l|}{ Gender } \\
\hline Male vs. Female & $1.42(0.89,2.26)$ & & \\
\hline BMI & $0.98(0.92,1.05)$ & & \\
\hline \multicolumn{4}{|l|}{ Type of dialysis } \\
\hline HD vs. PD & $5.53(2.18,14.04)^{*}$ & $1.83(0.64,5.21)$ & 0.258 \\
\hline Duration of Dialysis & $0.99(0.99,1.01)$ & & \\
\hline \multicolumn{4}{|l|}{ DM } \\
\hline Yes vs. No & $4.46(2.74,7.24)^{*}$ & $2.88(1.58,5.25)$ & $0.001^{*}$ \\
\hline \multicolumn{4}{|l|}{ HT } \\
\hline Yes vs. No & $0.95(0.57,1.60)$ & & \\
\hline \multicolumn{4}{|l|}{ Hyperlipidemia } \\
\hline Yes vs. No & $1.31(0.83,2.09)$ & & \\
\hline \multicolumn{4}{|l|}{ Smoking } \\
\hline Yes vs. No & $1.77(1.08,2.91)^{*}$ & $1.37(0.74,2.54)$ & 0.322 \\
\hline Daugirdes Kt/N & $0.68(0.36,1.26)$ & & \\
\hline $\mathrm{Hct}$ & $1.02(0.97,1.08)$ & & \\
\hline $\mathrm{TCO}_{2}$ & $1.00(0.92,1.08)$ & & \\
\hline Albumin & $0.47(0.26,0.85)^{*}$ & $0.98(0.45,2.17)$ & 0.963 \\
\hline i-PTH & $0.98(0.97,0.99)^{*}$ & $0.99(0.98,1.01)$ & 0.307 \\
\hline Ferritin & $1.00(1.001 .01)^{*}$ & $1.00(0.99,1.01)$ & 0.706 \\
\hline Cholesterol & $1.00(0.99,1.01)$ & & \\
\hline TG & $1.00(0.99,1.01)$ & & \\
\hline Blood sugar & $1.00(1.00,1.01)^{*}$ & $1.00(0.99,1.01)$ & 0.383 \\
\hline $\mathrm{Cr}$ & $0.72(0.65,0.80)^{*}$ & $0.85(0.74,0.98)$ & $0.024^{*}$ \\
\hline Uric Acid & $0.87(0.73,1.05)$ & & \\
\hline $\mathrm{Ca}$ & $1.00(0.76,1.33)$ & & \\
\hline$P$ & $0.85(0.71,1.01)$ & & \\
\hline $\mathrm{CaxP}$ & $0.99(0.97,1.01)$ & & \\
\hline
\end{tabular}

* Statistically significant $(\mathrm{P}<0.05)$.

the levels of serum ferritin, inflammatory biomarkers, and mortality in patients with PAD [20].

Another interesting finding of the present study is that the risk factors for PAD were different in HD patients and PD patients. In particular, pooling all patients together indicated that the risk factors for PAD were similar to those reported in the literature (Table 3). However, separate analysis of the two groups indicated that the risk factors in the HD group remained almost the same as for all patients (Table 4), but that there were no significant risk factors for the PD patients (Table 5). This indicates that further study of additional factors may be
Table 4 Univariate and multivariate logistic regression analysis of risk factors associated with peripheral artery disease (PAD) in hemodialysis (HD) patients $(n=380)$

\begin{tabular}{lllll}
\hline Variables & Univariate & & Multivariate & \\
\cline { 2 - 2 } & OR $(\mathbf{9 5 \%}$ C.I.) & & OR $(\mathbf{9 5 \%}$ C.I.) & P-value \\
\hline Age & $1.10(1.07,1.13)^{*}$ & & $1.09(1.06,1.13)$ & $<0.001^{*}$ \\
Gender & & &
\end{tabular}

\begin{tabular}{|c|c|c|c|}
\hline Male vs. Female & $1.36(0.84,2.22)$ & & \\
\hline BMI & $0.99(0.92,1.07)$ & & \\
\hline Duration of Dialysis & $0.99(0.99,1.01)$ & & \\
\hline \multicolumn{4}{|l|}{ DM } \\
\hline Yes vs. No & $4.05(2.43,6.74)^{*}$ & $3.36(1.80,6.25)$ & $<0.001^{*}$ \\
\hline \multicolumn{4}{|l|}{ HT } \\
\hline Yes vs. No & $1.07(0.61,1.87)$ & & \\
\hline \multicolumn{4}{|l|}{ Hyperlipidemia } \\
\hline Yes vs. No & $1.42(0.87,2.31)$ & & \\
\hline \multicolumn{4}{|l|}{ Smoking } \\
\hline Yes vs. No & $1.46(0.87,2.45)$ & & \\
\hline Daugirdes Kt/N & $1.15(0.58,2.26)$ & & \\
\hline $\mathrm{Hct}$ & $1.01(0.95,1.07)$ & & \\
\hline $\mathrm{TCO}_{2}$ & $1.17(1.02,1.30)^{*}$ & $0.98(0.85,1.14)$ & 0.832 \\
\hline Albumin & $0.33(0.17,0.65)^{*}$ & $0.99(0.43,2.27)$ & 0.981 \\
\hline i-PTH & $0.99(0.98,1.00)^{*}$ & $1.00(0.99,1.00)$ & 0.213 \\
\hline Ferritin & $1.00(0.99,1.01)$ & & \\
\hline Cholesterol & $1.00(0.99,1.01)$ & & \\
\hline TG & $1.00(0.99,1.01)$ & & \\
\hline Blood sugar & $1.00(1.00,1.01)^{*}$ & $1.00(0.99,1.01)$ & 0.322 \\
\hline $\mathrm{Cr}$ & $0.73(0.65,0.82)^{*}$ & $0.86(0.74,1.01)$ & 0.059 \\
\hline Uric Acid & $0.81(0.67,0.99)^{*}$ & $1.06(0.83,1.37)$ & 0.626 \\
\hline $\mathrm{Ca}$ & $1.14(0.83,1.55)$ & & \\
\hline$P$ & $0.92(0.77,1.10)$ & & \\
\hline CaxP & $0.99(0.98,1.01)$ & & \\
\hline
\end{tabular}

* Statistically significant $(p<0.05)$.

needed to better understand the risk for PAD in PD patients.

Our study has several limitations. First, this was a retrospective study, so there may have been errors due to confounding and bias. Second, the study period was only four months, so we cannot make any conclusions about the long-term outcomes. Third, all of our patients were from a single medical center in Taiwan, so our results may not be generalizable to other medical centers in Taiwan or elsewhere. Fourth, our use of ABI for diagnosis of PAD may have led to some misdiagnosis in patients with vessel calcification, leading to false negative diagnoses (type II errors). This limitation could have been overcome by use of toe plethysmography. Finally, we had no records of C-reactive protein, and use of 


\section{Table 5 Logistic regression analysis of risk factors associated with peripheral artery disease (PAD) in peritoneal dialysis $(P D)$ patients $(n=104)$}

\begin{tabular}{|c|c|}
\hline \multirow[t]{2}{*}{ Variables } & \multirow{2}{*}{$\begin{array}{l}\text { Univariate } \\
\text { OR (95\% C.I.) }\end{array}$} \\
\hline & \\
\hline$\overline{\text { Age }}$ & $1.03(0.96,1.10)$ \\
\hline \multicolumn{2}{|l|}{ Gender } \\
\hline Male & $1.12(0.18,6.70)$ \\
\hline Female & 1.00 \\
\hline BMI & $0.90(0.69,1.18)$ \\
\hline Duration of Dialysis & $1.00(0.98,1.02)$ \\
\hline \multicolumn{2}{|l|}{ DM } \\
\hline No & 1.00 \\
\hline Yes & $3.22(0.50,20.74)$ \\
\hline \multicolumn{2}{|l|}{ HT } \\
\hline No & 1.00 \\
\hline Yes & $0.23(0.04,1.43)$ \\
\hline \multicolumn{2}{|l|}{ Hyperlipidemia } \\
\hline No & 1.00 \\
\hline Yes & $1.66(0.27,10.37)$ \\
\hline \multicolumn{2}{|l|}{ Smoking } \\
\hline No & 1.00 \\
\hline Yes & $4.41(0.67,28.96)$ \\
\hline Daugirdes Kt/N & $1.44(0.17,12.15)$ \\
\hline $\mathrm{Hct}$ & $1.02(0.82,1.21)$ \\
\hline $\mathrm{TCO}_{2}$ & $1.02(0.72,1.45)$ \\
\hline Albumin & $0.46(0.06,3.80)$ \\
\hline i-PTH & $0.99(0.98,1.01)$ \\
\hline Ferritin & $1.00(0.99,1.01)$ \\
\hline Cholesterol & 1.01 (0.99. 1.03) \\
\hline TG & $1.00(0.99,1.01)$ \\
\hline Blood sugar & $1.00(0.99,1.01)$ \\
\hline $\mathrm{Cr}$ & $0.76(0.54,1.07)$ \\
\hline Uric Acid & $0.74(0.31,1.76)$ \\
\hline $\mathrm{Ca}$ & $1.54(0.56,4.25)$ \\
\hline$P$ & $0.45(0.19,1.05)$ \\
\hline CaxP & $0.94(0.87,1.02)$ \\
\hline
\end{tabular}

statins and aspirin. Nonetheless, many of the factors which we found increased the risk of PAD can be modified by life style changes. A recent review of PAD noted the importance of risk-factor modification and appropriate pharmacological management for management of PAD [21]. Interestingly, a recent study of PAD in a multi-ethnic Asian population reported that pulse pressure, renal impairment, and a past history of stroke (in addition to traditional risk factors) were important determinants of PAD [22].

\section{Conclusions}

The present retrospective study of Taiwanese ESRD patients from a single center indicated that the overall prevalence of PAD was $18.2 \%$. The prevalence of PAD was greater in the HD group than the PD group, presumably because the PD group was younger and had a lower prevalence of diabetes mellitus. The risk factors associated with PAD were increased age, diabetes mellitus, longer duration of dialysis, low serum creatinine, hyperlipidemia, and elevated serum ferritin. Most of the risk factors for PAD were specific to $\mathrm{HD}$, and no analyzed factor was significantly associated with PAD in PD patients.

\section{Competing interests}

The authors declare that they have no competing interests.

\section{Authors' contributions}

C-CL and C-FP are guarantors of the integrity of the entire study; C-CL, C-JW, and C-FP are responsible for study concepts, study design, and definition of intellectual content; C-CL and C-FP are responsible for literature research; all authors are responsible for clinical studies and data acquisition; C-CL, C-JW, L-HC, and C-FP are responsible for data analysis and statistical analysis; C-CL and C-FP are responsible for manuscript preparation, manuscript editing, and manuscript review. All authors read and approved the final manuscript.

\section{Acknowledgements}

We thank Peter A. Ensminger who provided medical writing services on behalf of MedCom Asia, Inc.

\section{Author details}

'Division of Endocrinology and Metabolism, Department of Internal Medicine, Mackay Memorial Hospital, Taipei, Taiwan. ${ }^{2}$ Division of Nephrology, Department of Internal Medicine, Mackay Memorial Hospital, Taipei, Taiwan.

${ }^{3}$ Division of Hemodialysis and Peritoneal Dialysis, Department of Nursing, Mackay Memorial Hospital, Taipei, Taiwan. ${ }^{4}$ College of Medicine, Taipei Medical University, Taipei, Taiwan. ${ }^{5}$ Mackay Medicine, Nursing and Management College, Taipei, Taiwan.

Received: 4 May 2012 Accepted: 27 August 2012

Published: 3 September 2012

\section{References}

1. Foley RN, Parfrey PS, Sarnak MJ: Clinical epidemiology of cardiovascular disease in chronic renal disease. Am J Kidney Dis 1998, 32(Suppl 3):S112-S119.

2. O'Hare A, Johansen KJ: Lower-extremity peripheral arterial disease among patients with end-stage renal disease. J Am Soc Nephrol 2001, 12:2838-2847

3. Selvin $E$, Erlinger P: Prevalence of and risk factors for peripheral arterial disease in the United States. results from the national health and nutrition examination survey 1999-2000. Circulation 2004, 110:738-743.

4. Hirsch AT, Criqui MH, Treat-Jacobson D, et al: Peripheral arterial disease detection, awareness and treatment in primary care. JAMA 2001, 286:1317-1324.

5. Rajagopalan S, Dellegrottaglie S, Furniss AL, et al: Peripheral arterial disease in patients with end-stage renal disease-observations from the dialysis outcomes and practice patterns study (DOPPS). Circulation 2006, 114:1914-1922.

6. Criqui MH, Langer RD, Fronek A: Mortality over a period of 10 years in patients with peripheral arterial disease. N Engl J Med 1992, 326:381-386

7. Bartholomew JR, Olin JW: Pathophysiology of peripheral arterial disease and risk factors for its development. Cleve Clin J Med 2006, 73(suppl 4):S8-S14

8. O'Hare AM, Glidden DV, Fox CS, Hsu C: High revalence of peripheral arterial disease in persons with renal insufficiency: Results from the 
national health and nutrition examination survey 1999-2000. Circulation 2004, 109:320-323.

9. Tian S-L, Murphy M, Han Q-F, Lu X-H, Wang T: Prevalence and risk factors for peripheral artery disease among patients on maintenance peritoneal dialysis. Blood Purif 2010, 30:50-55.

10. Paraskevas Kl, Kotsikoris I, Koupidid SA, Giannoukas AD, Mikhailidis DP. Ankle-brachial index: A marker of both peripheral arterial disease and systemic atherosclerosis as well as a predictor of vascular events. Angiology 2010, 61:521-523.

11. Liu JH, Lin HH, Yang YF, et al: Subclinical peripheral artery disease in patients undergoing peritoneal dialysis: risk factors and outcome. Perit Dial Int 2009, 29:64-71.

12. Newman AB, Sutton-Tyrrell K, Vogt MT, Kuller LH: Morbidity and mortality in hypertensive adults with a low ankle/arm blood pressure index. JAMA 1993, 270:487-489.

13. Suominen V, Rantanen T, Venermo M, Saarinen J, Salenius J: Prevalence and risk factors for PAD among patients with elevated ABI. Eur J Vasc Endovasc Surg 2008, 35:709-714.

14. O'Hare AM, Hus C-Y, Baccehetti P, Johansen KL: Peripheral vascular disease risk factors among patients undergoing hemodialysis. J Am Soc Nephrol 2002, 13:497-503.

15. Ouriel K, McDonnell AE, Metz CE, Zarins CK: Critical evaluation of stress testing in the diagnosis of peripheral vascular disease. Surgery 1982, 91:686-693.

16. Yao ST, Hobbs JT, Irvine WT: Ankle systolic pressure measurements in arterial disease affecting the lower extremities. Br I Surg 1969, 56:676-679

17. Feringa $\mathrm{HHH}$, Karagiannis SE, Schouten O, et al: Prognostic significance of decline ankle-brachial index values in patients with suspected or known peripheral arterial disease. Eur J Vasc Surg 2007, 34:206-213.

18. Guerrero A, Montes R, Munoz-Tero J, et al: Peripheral arterial disease in patients with stages IV and V chronic renal failure. Nephrol Dial Transplant 2006, 21:3525-3531.

19. Tsunoda K, Shimajiri Y, Morita S, et al: Chronic kidney disease has a more powerful impact on peripheral arterial disease than metabolic syndrome in Japanese type 2 diabetic patients. Metab Syndr Relat Disord 2009, 7:323-326.

20. Depalma RG, Hayes WW, Chow BK, et al: Ferritin levels, inflammatory biomarkers, and mortality in peripheral arterial disease: a substudy of the iron (Fe) and atherosclerosis study (FeAST) trial. J Vasc Surg 2010, 51:1498-1503.

21. Muir RL: Peripheral arterial disease: Pathophysiology, risk factors, diagnosis, treatment, and prevention. J Vasc Nurs 2009, 27:26-30.

22. Subramaniam T, Nang EE, Lim SC, et al: Distribution of ankle-brachial index and the risk factors of peripheral artery disease in a multi-ethnic Asian population. Vasc Med 2011, 16:87-95.

doi:10.1186/1471-2369-13-100

Cite this article as: Lee et al:: Peripheral artery disease in peritoneal dialysis and hemodialysis patients: single-center retrospective study in Taiwan. BMC Nephrology 2012 13:100.

\section{Submit your next manuscript to BioMed Central and take full advantage of:}

- Convenient online submission

- Thorough peer review

- No space constraints or color figure charges

- Immediate publication on acceptance

- Inclusion in PubMed, CAS, Scopus and Google Scholar

- Research which is freely available for redistribution

Submit your manuscript at www.biomedcentral.com/submit
Biomed Central 